\title{
The importance of end-use technologies for long-term energy use in Sweden
}

\author{
M. Bladh \\ Department of Thematic Studies-Technology and social change \\ Linköping University, SE-581 83 Linköping, Sweden \\ +4613 284453; mats.bladh@liu.se
}

\begin{abstract}
Energy consumption has stagnated in Sweden since the 1970s. It is not known how this was accomplished, but increasing efficiency in consumption has played an important role. In order to understand this a Change-of-stock approach is presented. Basically this approach says that stocks of energy converting artefacts on the consumption side comprise mature technologies with advantages of a path dependent character. These advantages create obstacles for radical technological changes and pushes in favour of incremental changes within dominating technologies. For the sake of testing the relevance of this approach five cases are highlighted. Data over stocks and replacement rates are estimated in three cases. Both factual and counterfactual estimations are presented. What is tested is the fruitfulness of the Change-of-stock approach as a tool for analysis of longterm changes in energy efficiency.
\end{abstract}

Results from the cases show considerable gains of efficiency in fuel consumption in private cars, and heating efficiency in multi-dwelling houses. Thus incremental changes are important, but are partially offset by changes in characteristics of the artefacts. Radical changes, as the factual change from air to rail, and a counterfactual double switch from gasoline to electric cars and from electric heating to district heating, and probable gains from the phase-out of incandescent lamps, show even bigger gains. Both incremental and radical changes are subject of counteracting tendencies, of a broader nature than that associated with rebound effects, such as more cars per inhabitant and fewer people in each dwelling.

The approach seem to promise a way to analyse energy efficiency that captures both promoting and counteracting factors, and at both the micro and macro level.

Keywords: Stock, Replacement, Characteristic, Energy efficiency.

\section{Introduction}

In several countries energy consumption has been decoupled from economic growth since the 1970 s, one of which is Sweden [11]. Since the 1970s total energy consumption has stagnated despite a growth trend in GDP, and since the mid 1980s consumption of electricity has stagnated despite the role of electricity as a factor increasing overall energy efficiency. The oil price shocks initiated a switch of focus from supply to efficiency. Decoupling was a drawn-out affair as there is inertia due to past investments. Path dependence theory explains non-change basically with reference to cost advantages of existing technologies both on production and consumption side (for an introduction to path dependence see [2]). Today it is common to use an analogy to pedagogy, so that "learning curves" represents cost reductions in production of energy converters (in a broad sense) and in the familiarity in use of these converters. Due to cost advantages of widely used technologies the most likely path will be incremental change: Raising efficiency in gasoline cars instead of switching to electric cars, improving insulation in existing buildings instead of erecting passive houses, etc. When it comes to lighting the purchase price is much lower but the number of lamps make a radical break quite costly, and here we have the problem of the norm the warm glow of the incandescent as associated with.

Because sunk costs in stocks are important not only for the large number of units but also for the inertia it represents. IN THE FOLLOWING A CHANGE-OF-STOCK MODEL WILL BE TRIED OUT AS A STARTING POINT FOR THE ANALYSES. A point of departure for the model is the fact that energy is never used directly but always by way of some artefact - a paper machine, a car, a 
dwelling, a dishwasher, etc. [4]. There is a stock of machines, vehicles, buildings and appliances that demand energy. Every type of such energy converters comes in different models, and they are not only energy converters, they also have other qualities that are important for the buyer and user. A car, for instance, has several "characteristics" [6] of which fuel consumption is just one of many. THUS THE WORD “ARTEFACT" USED HERE STANDS FOR A COMPOSITE, OR COMPLEX UNIT. The stock is renewed through scrapping of old units, and through adding of new units. Additions can be of two kinds basically: Incremental improvements on technologies dominating the stock, or radically different technologies surviving at the margin of the stock.

A challenge for the efficiency strategy is the "rebound effect". It has been debated several times, beginning with Brookes' and Khazzoom's articles 1979 and 1980 (for an introduction see [7]). From an historical, or rather dynamic, point of view, the neoclassical formulation of the theory is limiting. As it stands it says basically that the acting factor (improvements in energy efficiency) causes a counteracting factor (increased use of the service in question or other services requiring energy) to operate. This narrow definition is too limited, for two reasons: First, counteracting tendencies can also work in parallel without direct link to prices and costs of particular type energy use. Increasing population, the decreasing number of people in the average household and new areas of consumption can increase the aggregate consumption of energy. Second, radical changes are associated with such drastic improvements in efficiency that it is impossible to outdo the gain through increased consumption.

WHAT IS TESTED HERE IS THE FRUITFULNESS OF THIS ‘CHANGE-OF-STOCK’ APPROACH.

\section{Method}

Three types of artefacts were chosen, all associated with private consumption (households) cars, dwellings and lamps. Data of aggregate stocks over the long-run were collected from different sources. For cars and multi-dwelling houses the rate of renewal was estimated, and fuel and heating consumption of the average car and dwelling respectively. Counterfactual developments were estimated where certain variables were held constant, such as carintensity, mileage per car, longer use-life of cars, and no energy-demanding changes in cars. Basically the same thing was done on heating of dwellings in multi-family houses. Due to lack of historical data the development of the residential lighting stock could not be disclosed. Instead data from a monitoring study performed by the Swedish Energy Agency was used for an estimation of the future of the Swedish residential lighting stock during the phase-out of incandescent lamps.

These incremental changes were contrasted with radical changes. In one it was estimated how much had been gained by the factual switch in long-distance domestic travel from air to rail, and in the other the aggregate effects of a counterfactual double-switch from gasoline to electric cars plus a switch from electric heating to district heating. The rationale for these cases is that in the first a radically different transport technology actually had been chosen, and in the other preferred choices of technologies from a sustainability point of view were estimated.

As society is an open system, one factor cannot be isolated as is possible in a laboratory experiment. Thus, whatever method used, the result cannot be unequivocal, and therefore can, and must, be the object of several possible interpretations. Counterfactual studies in social sciences can better be looked at as thought-experiments, in this study closely related to issues 
of trade-offs and choices of path in energy policy. When such problems and choices are discussed the relative magnitudes of gains in energy efficiency are of interest.

\section{Results}

\subsection{Cars}

The stock of private cars has been increasing in the long run, from 250,000 in 1950, to 2.5 million in 1973, and to 4.3 million in 2009. This rate of growth has exceeded the growth of population by far: In 1956 there were 10 inhabitants per car, in 2009 there were 2.2. Growth of the stock stagnated in the late 1970s and in the early 1990s. The age of the average car in 2009 is 9.3 years. [1].

The car is a complex durable commodity with several characteristics. The composition of characteristics of the average car changes through scrapping of old and adding of new cars. Energy efficiency is dependent not only of the energy conversion efficiency of the engine, but of several other characteristics, such as rate of acceleration, engine power, weight, air drag, the quality of tyres, etc. These characteristics, in turn, are connected to usefulness in terms of safety of driving, passenger and luggage space, low noise level and many others.

Sprei et al [16] investigated the conflicting tendencies in the composition of characteristics of new cars in Sweden: Better performance on on e hand and lower fuel consumption on the other. New cars in 1975, 1985, 1995 a nd 2002 were studied in regard to passenger space, luggage space, top speed, time for acceleration, frontal surface area, weight, maximum power, cylinder volume, and fuel consumption. They found that increased space, acceleration and weight had reduced the gains from technical improvements of the engine, air drag and rolling resistance of tyres. About 65 per cent of the possible gains had been eliminated by comfort and acceleration only 35 per cent came out as better fuel economy.

Table 1. Descriptive and counterfactual data on the stock of private cars in Sweden and their fuel consumption 1950-2009.

\begin{tabular}{lrrr}
\hline & $\mathbf{1 9 5 0 - 5 9}$ & $\mathbf{1 9 7 0 - 7 9}$ & $\mathbf{2 0 0 0 - 0 9}$ \\
\hline A. No of cars in stock, millions & 0.62 & 2.65 & 4.14 \\
\hline B. Inhabitant per car & 11.5 & 2.9 & 2.0 \\
\hline C. New cars as share of stock, \% & 17.9 & 8.9 & 6.5 \\
\hline D. Scrapped cars as share of stock, \% & 4.3 & 6.7 & 5.7 \\
\hline E. Mileage, passenger km, billions & 16.6 & 63.8 & 96.4 \\
\hline F. Mileage per car, km & 26774 & 24075 & 22419 \\
\hline G. Fuel consumption per car, 1/100 km & & 10.15 & 8.32 \\
\hline H, a. Total fuel consumption, index & 100 & 115 \\
\hline b. Index when B and F constant & 100 & 96 \\
\hline c. Slower renewal of stock & & 100 & 119 \\
\hline d. Only energy-saving features new cars & 100 & 112 \\
\hline
\end{tabular}

The average car consumed 8.32 litres per 100 kilometres when the factual development was estimated, and 8.08 when a possible development of smaller, slower and lighter cars was calculated (index value 112 in the last row). The slower renewal of the stock is estimated as the equivalent to the average fuel consumption of the stock in the period 1990-99. The average car of such a stock would have been very old, about 20 years (index value 119 next to last row). When car intensity and mileage per car is held constant at the 1970-79 level, total fuel consumption in 2000-09 is not only lower than it actually was, but also lower than in the 1970s, despite the fact that mileage was higher in the 1970s [14]. Note that in this 
counterfactual case the number of cars has been allowed to increase in parallel to the size of the population. The rate of replacement is in the long run slowing down, additions more so than scrappings (row C and D).

\subsection{An imagined double switch to and from electricity}

What would a double conversion-replacing electric heating with district heating, and replacing petrol cars with electric cars - mean for total energy consumption in Sweden? Assumptions used were $20 \%$ efficiency for combustion engine and $70 \%$ for electric motor [15], and $95 \%$ for electric heating and $84 \%$ for district heating [5]. The phase-out of electric heating and phase-in of electric cars were distributed equally for each year over a 30 yearperiod, 1975-2006. Input data on petrol ("bensin", excluding diesel) refers to total use of petrol in the transport sector, not only for private cars, and is thus exaggerated. It is assumed that electric heating will be replaced by combined heat and power production in district heating systems, but the additional electric energy produced has not been added to the total amount of electricity (which is a measure of consumption, not production). The fuel used in this counterfactual increase in CHP is left unspecified.

Table 2. Estimated changes in energy consumption when gasoline cars are replaced by electric cars, and electric heating with district heating.

\begin{tabular}{lrrr}
\hline & TWh 1975 & TWh 2006 & Index 2006 \\
\hline Gasoline cars, factual & 38.2 & 45.2 & 100 \\
\hline Electric cars, counterfactual & 10.9 & 12.9 & 29 \\
\hline Electric heating, factual & 9.3 & 22.1 & 100 \\
\hline District heating, counterf. & 10.5 & 25.0 & 113 \\
\hline
\end{tabular}

Replacing gasoline cars with electric cars would reduce energy consumption with $32.3 \mathrm{TWh}$, while replacing electric heating with district heating would increase consumption with 2.9

TWh. The net gain would thus be 29.4 TWh.

\subsection{Dwellings}

The housing stock changes through a combination of building new and scrapping or rebuilding old houses. During a long post-war period, from 1959 to 1975, new build dominated restructuration with more than 60,000 dwellings per year (a peak occurred also around 1991). Since 1993 renovation of existing dwellings has dominated, at least in regard to multi-dwelling houses where reliable statistics is at hand.

Table 3. Descriptive and counterfactual data on the stock of dwellings in multi-family houses 1980, 1990 and 2008.

\begin{tabular}{lrrr}
\hline & $\mathbf{1 9 8 0}$ & $\mathbf{1 9 9 0}$ & $\mathbf{2 0 0 8}$ \\
\hline A. No of dwellings in stock, thousands & 2043 & 2171 & 2440 \\
\hline B. Persons per dwelling & 1.70 & 1.51 & 1.53 \\
\hline C. Change of stock, \% & 1.3 & 2.6 & 1.9 \\
\hline D. Square meter per dwelling & 65 & 78 & $* 80$ \\
\hline E. Heating per square meter, kWh & 295 & 190 & 145 \\
\hline F, a. Total heating, TWh & 39.2 & 21.1 & 28.3 \\
\hline F, b. Total heating, index & 100 & 82 & 72 \\
\hline F, c. Index when B and D constant & 100 & 66 & 55 \\
\hline F, d. Index when E is constant & 100 & 127 & 147 \\
\hline F, e. Index when B, D and E constant & 100 & 103 & 111 \\
\hline
\end{tabular}


Source: [9] [10] [12]. * = guess.

The last census, including housing conditions, was made in 1990. A fter that date data on housing has not been renewed at the same level of quality. This is the reason why a guess had to be made concerning the size of the average dwelling in 2008. Change of stock (row C) includes demolished, refurbished as well as new built houses. The rate of replacement $(2 \%)$ is much lower than for the car stock (12-13\%). Efficiency of heating has improved considerably since 1980, especially during the 1980s (and probably during the 1970s too, if the trend for multi-dwelling houses followed that of the small houses). Total heating has thus been reduced despite a growing number of dwellings.

When household formation and size of the average dwelling is held constant, total heating is reduced even more (see row $\mathrm{F}, \mathrm{c}$ ). If improvements in heating efficiency would stop at the 1980 level, 47 per cent more energy would have been consumed (row F, d). If changes in household formation and changes in the stock would have been neutral in regard to dwelling size and heating efficiency, then total heating would have been higher than it was in 1980.

\subsection{A real switch from air to rail}

According to statistics domestic air travel (from and to destinations within Sweden) increased from 1970 to 1990 [14]. After this year domestic air stagnated - in 2008 it was still lower than it was in 1990. Travel by railroad stagnated 1980-1992 but increased quite fast after this period. It seems that a change has occurred in the choice between train and aviation in longdistance domestic travel, in favour of train and thereby a switch from aviation fuel to electricity. If this interpretation is correct the change has lowered energy consumption for this purpose. A CALCULATION HAS BEEN MADE OF THE ENERGY CONSUMPTION IN TWO CASES: One the factual case, and a counterfactual case where rail had followed a stagnating trend while air had increased. In the factual case $13 \mathrm{TWh}$ were used for domestic travel, in the counterfactual case $20 \mathrm{TWh}$ - quite big a difference.

\subsection{Lamps}

We do not know so much about the lighting stock. The most comprehensive study made so far, is that by the SEA 2005-2008. Data from this source is shown in Table 4.The studies made so far are not representative of the whole household population. The number of households covered is small, from a statistical reliability point of view, due to the fact that data collection is cumbersome as the hours-of-use is essential information to collect.

Table 4. Unweighted averages on Swedish household's use of electric lighting 2005-2008.

\begin{tabular}{lrr}
\hline & Small houses & Multi-dwelling houses \\
\hline Number of lamps & 55.2 & 31.2 \\
\hline Wattage per lamp (W) & 29.3 & 26.6 \\
\hline Hours-of-use per day and lamp & 1.60 & 1.94 \\
\hline Number of households (000) & 1,978 & 2,238 \\
\hline Electricity for lighting (TWh) & 1.87 & 1.31 \\
\hline Lighting/all electricity (\%) & 22.7 & 19.0 \\
\hline
\end{tabular}

Sources: [17], [18], [8]. "Small houses" include detached houses and houses with two dwellings. "Multi-dwellings houses" often contain shops, offices and other non-residential spaces, but the main purpose is residential.

The sample is small in relation to the population of households, and the geographical distribution of the sample is quite narrow. On the other hand data covers several types of 
households in regard to housing, age, number of people, etc., and it is very detailed comprising observations on each appliance. With this in mind, we can let data give us a hint of what the national consumption of electricity for lighting would look like. From data in Table 4 it can be calculated that there are 179 million lamps in total.

Table 5. The distribution on lamp types in Swedish households, and assumed lifetime and price level for each type. Per cent, hours, Euro.

\begin{tabular}{lrrr}
\hline Lamp type & Share, \% & Life time, h & Price level, $€$ \\
\hline Incandescent & 60.5 & 1000 & 1 \\
\hline Halogen & 16.2 & 3000 & 4 \\
\hline CFL & 13.1 & 7000 & 6 \\
\hline Fluorescent tubes & 10.2 & 10000 & 6 \\
\hline
\end{tabular}

Sources: [17], [13]. Currency rate assumed: $10 \mathrm{SEK}=1 € .1 \mathrm{USD} \approx 0.75 €$ in May 2010.

The effects of the phase-out [3] can be described as a comparison of the residential lighting stock before and after the transition period. It is assumed that all incandescent lamps will disappear and be replaced by CFL and halogen lamps. Then the replacement rate will decrease from 43 to 14 per cent per year (or from 2.3 years to 7.1 years for the whole stock to be replaced). Average power will be lower and thus electricity consumption for lighting (assuming constant hours-of-use).

Table 6. Economics of the phase-out.

\begin{tabular}{lrr}
\hline & 2010 & 2013 \\
\hline Replacement rate, \% & 43 & 14 \\
\hline Power per lamp, W & 28 & 18 \\
\hline Electricity for residential lighting, TWh & 3.2 & 2.1 \\
\hline Lamp sales, m€ & 113 & 119 \\
\hline Electricity sales, $\mathrm{m} €$ & 483 & 308 \\
\hline
\end{tabular}

"m€" = millions of Euro.

\section{Concluding discussion}

The change of stock approach says that the stock consists of mature energy converting technologies with cost advantages in production and advantages of familiarity among consumers and users. Because of these advantages an incremental path of improvements in energy efficiency is often chosen, the path of improvements of dominating technologies. For example higher fuel efficiency of the combustion engine, and additional insulation of existing houses.

Radical changes through the introduction of basically different technologies meet barriers of entry and must overcome the obstacles associated with path dependence. They are implemented only at the margin of the stock and meet increasingly higher barriers as dominating technologies are improved upon. This explains why the electric car has difficulties to gain wide diffusion.

Incremental changes in energy efficiency can be displaced by changes in other characteristics counteracting the efficiency gain. A heavier car, for instance, requires a more powerful engine, which can partially or completely outdo improvements of the engine. The compound effects of all relevant changes are what matters. Nevertheless, estimations of energy efficiency improvements shown in this paper have been quite substantial, more so in heating than for cars. Still, radical changes, such as a double switch from gasoline to electric cars and 
from electric heating to district heating would not only include a higher gain in efficiency but also a change of path.

The phase-out of incandescent lamps is a special case as it relies on a long period of preparation. The CFL has been around since the 1980s and is now more competitive in terms of purchase cost and familiarity among the public. The phase-out pushes consumers over the last threshold of a somewhat higher purchase price and forcing the user to forget the warm glow of the incandescent.

In the 1990s in Sweden there occurred a switch from air to rail in long-distance travel within the country. Many passengers changed their mode of transportation in favour of the train. This switch was a switch from the use of one existing stock to another, rather than a change of one stock. Energy saved from this switch was considerable.

There are, however, counteracting tendencies of a more purely social nature that partially outdo the gains efficiency in the more purely technological sense. Increasing population, a higher number of cars per head, and fewer people in the average household, are examples of such tendencies. They play a significant role for the total consumption of energy.

The strength of the change-of-stock approach is that it enables us to capture both promoting and offsetting factors, and both details and aggregate effects of changes related to energy efficiency in consumption. Taking the stock into consideration has implications for the future: The stock will be there in the future, it represents decisions of yesterday and today. Old innovations, both conservative and radical, may result in improvements in energy efficiency but are dependent on what is added to and scrapped from the stock and shifts between stocks.

\section{References}

[1] Bil Sweden, Statistik, 2010, http://www.bilsweden.se/web/Ny_statistik.aspx

[2] M. Bladh, Spårbundenhet. Från fysik till historia, Historisk tidskrift, 128, 2008:4, pp. 671692.

[3] EC, European Commission, Commission Regulation (EC) No 244/2009 of 18 March 2009 implementing Directive 2005/32/EC of the European Parliament and of the Council with regard to ecodesign requirements for non-directional household lamps. 2009. http://eurlex.europa.eu/smartapi/cgi/sga_doc?smartapi!celexplus!prod!DocNumber\&lg=e n\&type_doc=Regulation\&an_doc=2009\&nu_doc $=0244$ (downloaded 2009-10-06).

[4] R. B. Howarth, Energy efficiency and economic growth, Contemporary Economic Policy, XV, 1997, pp. 1-9.

[5] T. B. Johansson \& P. Steen, Perspektiv på energi. Om möjligheter och osäkerheter inför energiomställningen. Stockholm: Liber, Energiforskningsnämnden, 1985, pp. 319, 321.

[6] K. J. Lancaster, A new approach to consumer theory, Journal of Political Economy, April 1966, 74, 1966:2, pp. 132-157.

[7] R. Madlener \& B. Alcott, Energy rebound and economic growth: A review of the main issues and research needs, Energy, 34, 2009, pp. 370-376.

[8] SCB, Antal hushåll (HEK) efter hushållstyp, boendeform och tid, referring to 2006. Extract from database, Statistics Sweden, 2008, http://www.scb.se, downloaded 2008-1104. 
[9] SCB, Yearbook of Housing and Building Statistics 2010. Stockholm: Statistiska centralbyrån, 2010.

[10] SEA, Effektiv energianvändning - en analys av utvecklingen 1970-1998. ER 22:2000. Swedish Energy Agency, 2000.

[11] SEA, Energy in Sweden. Facts and figures 2009. Swedish Energy Agency, 2009. Downloaded from http://www.energimyndigheten.se, January 2010.

[12] SEA, Energy statistics for dwellings and non-residential premises (several publications 2000-2008 from the same series). Swedish Energy Agency. Downloaded from http://www.energimyndigheten.se, June 2010.

[13] SEA, Hushållen tycker att energieffektiv belysning är bra, press release from the Swedish Energy Agency, 2010-04-28.

[14] SIKA, SIKA Basfakta, 2010. http://www.sika-institute.se/Templates/Page 1785.aspx

[15] V. Smil, Energy in Nature and Society. General Energetics of Complex Systems. Cambridge: MIT, 2008, p. 395.

[16] F. Sprei, S. Karlsson \& J. Holmberg, Better performance or lower fuel consumption: Technological development in the Swedish new car fleet 1975-2002, Transportation Research Part D, 13, 2008, pp. 75-85.

[17] J. P. Zimmerman, End-use metering campaign in 400 households in Sweden. Assessment of the potential electricity savings. Enertech \& Energimyndigheten, 2009.

[18] E. Öfverholm, sheet with data from the monitoring study performed by the Swedish Energy Agency, 2009. 